\title{
Risk of spontaneous abortion in women occupationally exposed to anaesthetic gases: a meta-analysis
}

Jean-François Boivin

\begin{abstract}
Objectives-To determine the association between maternal occupational exposure to anaesthetic gases and risk of spontaneous abortion.
\end{abstract}

Methods-A meta-analysis was performed of published epidemiological studies identified from literature reviews, unsystematic perusal of reference lists of relevant publications, and two Medline searches (1984-92, keywords: anaesthetic gases; anaesthetics; anaesthetics, local; operating rooms; operating room nursing; pregnancy; abortion; 1985-92, keywords: anaesthetics; adverse effects; occupational exposure; anaesthesia, inhalation; operating room nursing; pregnancy; abortion). All peer reviewed studies were retained. Student theses were excluded, as were conference abstracts, unpublished material, and two studies in which data on paternal and maternal occupational exposures were pooled. The relative risk of spontaneous abortion was estimated.

Results-One study found no increase in risk of abortion when gases were scavenged or when the exposure to unscavenged gases was low. None of the studies included ambient gas sampling. 24 comparisons between exposed and unexposed women, obtained from 19 reports, were included. The overall relative risk was 1.48 (95\% confidence interval (95\% CI), 1.4 to 1.58). To test whether this result was influenced by the quality of the studies, the validity of the reviewed papers was rated on the basis of three criteria: appropriateness of the unexposed comparison group, control for non-occupational confounding variables, and response rate. The estimate of risk increased to $1.9(95 \% \mathrm{CI}, 1.72$ to 2.09) when analysis was restricted to the six comparisons which were rated the most rigorous.

Conclusions-Epidemiological studies based on data obtained in the prescavenging era indicate an increased risk of spontaneous abortion. The estimated increased risk was not diminished but rather increased by exclusion of the more methodologically flawed studies.

(Occup Environ Med 1997;54:541-548)

Keywords: spontaneous abortion; anaesthetic gases; occupational exposure
Since 1971 , many epidemiological studies have assessed the risk of spontaneous abortion, birth defects, and other reproductive outcomessuch as reduced fertility-after occupational exposure to anaesthetic gases. Several of these studies reported positive associations between exposure and adverse reproductive outcomes and this led to awareness of this potential occupational hazard and stimulated the improvement of ventilation systems, particularly through the introduction of systems by which expired air containing anaesthetic gases is "scavenged" in hospital operating rooms. Despite these environmental improvements, concerns continue to exist. In 1994, the United States National Institute for Occupational Safety and Health (NIOSH) published a report which included a warning indicating that workers exposed to nitrous oxide may have harmful effects. ${ }^{1}$ In the province of Québec, Canada, the Occupational Health and Safety Act gives pregnant women the right to protective reassignment or leave if their working conditions present a physical danger to them or to their child. In the application of this law, the evaluation of danger in the workplace must be conducted by a physician.

The purpose of the present report is to review the existing epidemiological studies on the risk of spontaneous abortion after occupational exposure to anaesthetic gases. The results of these studies are conflicting, ranging from reduced risk to a twofold to threefold increase in risk. None obtained atmospheric measurements of exposure to anaesthetic gases and most were carried out before scavenging was widely used. They also contain several methodological difficulties which render their validity uncertain. We review all the available epidemiological studies, and carry out a metaanalysis of their results. Also, to evaluate whether methodological defects may have influenced the outcome of the meta-analysis, we awarded each study a score to reflect the defects which could be identified.

\section{Methods}

We identified epidemiological studies of spontaneous abortion among women occupationally exposed to inhalation anaesthetics through Medline searches, from published reviews of the literature, from the unsystematic perusal of journals, and from reference lists of various papers. Two Medline searches were conducted. The first search covered the years 1984-92 and used the following keywords: anaesthetic gases; 
anaesthetics; anaesthetics, local; operating rooms; operating room nursing; pregnancy; and abortion. The second search included the years 1985-92 and the keywords were: anaesthetics; adverse effects; occupational exposure; anaesthesia; inhalation; operating room nursing; pregnancy; and abortion. We searched the literature published in English and in French. We retained only published peer reviewed papers and we therefore excluded documents such as student's theses and conference abstracts. We did not systematically search unpublished material. We restricted our analyses to data on maternal occupational exposures. We therefore excluded a report by Cohen et $a l^{2}$ which only assessed spontaneous abortions in wives of oral surgeons and dentists. When a study reported data on both paternal and maternal occupational exposure, we only reviewed the maternal data. ${ }^{3-9}$ We excluded two studies in which data on paternal and maternal occupational exposure were pooled and could not be examined separately. ${ }^{1011}$

The assessment of the validity of each paper was based on three criteria: appropriateness of the unexposed comparison group, control for non-occupational confounding variables, and response rate to questionnaires or other survey instruments. The measure of association chosen for the meta-analysis was the relative risk. For 17 follow up studies, the relative risk was estimated as the ratio of the rate of spontaneous abortion in exposed women to the ratio in unexposed women, adjusted for covariates or not, depending on what was available in the reviewed reports. For two case-control studies, the estimate of the relative risk was the odds ratio, which tends to overestimate slightly the relative risk when the disease under study is not rare. We weighted each relative risk estimate according to the inverse of its variance. ${ }^{1213}$ All data used for the meta-analysis were extracted by the author.

\section{ASSESSMENT OF THE VALIDITY OF REPORTED RESULTS}

We identified 19 reports for our meta-analysis, including 17 historical follow upstudies ${ }^{3-7914-24}$ and two case-control studies. ${ }^{825}$ Occupational exposure to anaesthetic gases was assessed in several studies through postal questionnaires to the mothers ${ }^{3-914-1618192223}$ or, less often, by face to face interviews. ${ }^{16202124}$ In one study, industrial hygienists evaluated occupational exposures based on information provided by the mother. ${ }^{21}$ Other strategies included questionnaires to head nurses, ${ }^{25}$ and the review of employment and hospital records. ${ }^{1725}$ Spontaneous abortions were generally reported by respondents without further validation. In five studies, hospital records or registry data were used either to supplement self reported data, or as the sole source of information. ${ }^{1517182025}$ In nine reports, no definition of spontaneous abortion was provided; $45781517-1923$ in one of these studies, ${ }^{8}$ stillbirths were apparently included in the analyses with the cases of spontaneous abortion. In other reports, the following definitions were given: abortion before the 20th week of pregnancy ${ }^{369}$; before the 21 st week $^{1416}$; and before the 28th week. ${ }^{20-22}{ }^{24}$ Hemminki et $a l^{25}$ included hospital discharge diagnoses corresponding to codes 643 and 645 of the eighth revision of the international classification of diseases (ICD-8) ${ }^{26}$

Tables 1 and 2 identify the occupational groups which were contrasted in each study. Exposed women included nurses, physicians, technicians, dental assistants, veterinarians, and veterinary assistants; in certain studies, the job title was defined in more general terms such as operating room worker, hospital worker, or health worker. Unexposed reference groups generally included women from these same occupational groups, but unexposed to anaesthetic gases. In some cases, unexposed women were chosen from any occupational group, related or not to the health sector, or were not in any formal employment. In certain reports, more than one analysis was presented, contrasting different occupational groupssuch as nurses or physicians.

CONTROL OF OCCUPATIONAL CONFOUNDING VARIABLES THROUGH SELECTION OF ADEQUATE COMPARISON GROUPS

Savitz et $a l^{77}$ showed that in reproductive occupational studies, confounding biases may arise in the comparison of exposed and unexposed women when the unexposed comparison group consists of women not working during pregnancy. These authors found in a survey of pregnancies of 3712 employed and 2215 unemployed women that employed mothers were of more optimal reproductive age, were more highly educated, had higher incomes, began perinatal care earlier, had greater weight gain during pregnancy, and were slightly less likely to be heavy smokers; employed women also had considerably fewer previous births and more stillbirths and miscarriages than unemployed women. These authors concluded that these differences could produce bias in studies of work and reproductive health, and that reproductive health should not be compared directly between working women and nonworking women. We therefore assumed in our review that studies which used as their unexposed comparison group women who were not working during the relevant exposure time window-for example, during the first or second trimester of pregnancy-were more likely to be biased than those restricted to working women.

Other confounding biases may also be present. Factors related to the work environment of women exposed to anaesthetic gases may be associated with the risk of spontaneous abortion. These include standing, lifting heavy weights, other physical effort, long hours of work, and changing shift work. ${ }^{2021}$ The literature on this question is not unanimous ${ }^{28}$ and some uncertainty exists on this issue. However, we judged that the preponderance of scientific data is in favour of the assumption that ergonomic demands and other occupational characteristics of exposed women may represent confounding variables. We therefore gave more weight to studies selecting unexposed comparison groups very similar to the exposed 
groups for these potential confounding variables. On the basis of this criterion, we judged that studies which included in their unexposed comparison group women who were not employed in the health sector ${ }^{4152021}$ were more likely to be biased than those restricted to women from the health service. Within health related occupations, some comparison groups may be preferable to others. Cohen et $a l^{3}$ for example, reported an incidence of spontaneous abortion of $17.1 \%$ among anaesthetists exposed to anaesthetic gases during the year before pregnancy and the first trimester of pregnancy. In unexposed paediatricians the incidence was $8.9 \%$. Among unexposed anaesthetists, however, the rate of miscarriage was $15.7 \%$, still well above that of unexposed paediatricians. This suggests that paediatricians do not represent a valid comparison group for anaesthetists, perhaps because of the different nature of their work, possibly involving less ergonomic demands. It may be, however, that it is the unexposed anesthetists who represent a biased comparison group, because of unmeasured confounding factors associated with the fact that they did not work in anesthesia at the time of their pregnancy.

In certain reports, comparison groups seemed very appropriate. Rosenberg and Kirves, ${ }^{23}$ for example, compared exposed "scrub" (operating room) or anesthesia nurses to unexposed emergency or intensive care nurses. If stress and long hours standing represent confounding variables, the chosen unexposed group probably constituted a valid comparison group. Similarly, other authors presented comparisons of exposed and unexposed dental assistants, ${ }^{61418}$ veterinarians, ${ }^{8}$ or veterinary assistants. ${ }^{8}$

Table 1 Follow up studies of spontaneous abortion in women occupationally exposed to anaesthetic gases

\begin{tabular}{|c|c|c|c|c|c|c|c|}
\hline \multirow{3}{*}{$\begin{array}{l}\text { Reference } \\
\text { Cohen et al } 1971^{16}\end{array}$} & \multirow{2}{*}{\multicolumn{2}{|c|}{$\begin{array}{l}\text { Exposed group } \\
\text { Number of pregnancies and occupation }\end{array}$}} & \multicolumn{2}{|c|}{ Time window for } & \multicolumn{3}{|c|}{ Unexposed group } \\
\hline & & & \multirow{2}{*}{$\begin{array}{l}\text { Inclusion of } \\
\text { pregnancies }\end{array}$} & \multirow{2}{*}{$\begin{array}{l}\text { Occurrence of exposure } \\
5 \text { y before pregnancy }\end{array}$} & \multicolumn{2}{|c|}{ Number of pregnancies and occupation } & \multirow{2}{*}{$\frac{\text { Score }^{*}}{1}$} \\
\hline & 36 & Operating room nurses & & & 34 & $\begin{array}{l}\text { Nurses not in operating room (probably } \\
\text { working) }\end{array}$ & \\
\hline & 37 & Anaesthetists & $6 \mathrm{y}$ & 6 y before pregnancy & 58 & Other physicians (probably working) & 1 \\
\hline $\begin{array}{l}\text { Knill-Jones et al } \\
1972^{19}\end{array}$ & 737 & Anaesthetists & Lifetime & 1 st or 2 nd trimester & 2150 & $\begin{array}{l}\text { Other physicians (working status } \\
\text { unknown) }\end{array}$ & 1 \\
\hline $\begin{array}{l}\text { Rosenberg and } \\
\text { Kirves } 1973^{23}\end{array}$ & 257 & Scrub, anaesthesia nurses & $8 y$ & During pregnancy & 150 & $\begin{array}{l}\text { Emergency, intensive care nurses } \\
\text { (working) }\end{array}$ & 2 \\
\hline \multirow[t]{3}{*}{ Cohen $1974^{3}$} & 468 & Anaesthetists & $10 y$ & $\begin{array}{l}\text { Year before pregnancy } \\
\text { and lst trimester }\end{array}$ & 138 & $\begin{array}{l}\text { Unexposed anaesthetists (working status } \\
\text { unknown) }\end{array}$ & 1 \\
\hline & 1826 & Nurse anaesthetists & $10 y$ & $\begin{array}{l}\text { Year before pregnancy } \\
\text { and 1st trimester }\end{array}$ & 676 & $\begin{array}{l}\text { Unexposed nurse anaesthetists (working } \\
\text { status unknown) }\end{array}$ & 1 \\
\hline & 2781 & $\begin{array}{l}\text { Operating room nurses, } \\
\text { technicians }\end{array}$ & $10 y$ & $\begin{array}{l}\text { Year before pregnancy } \\
\text { and 1st trimester }\end{array}$ & 1533 & $\begin{array}{l}\text { Unexposed operating room nurses, } \\
\text { technicians (working status unknown) }\end{array}$ & 1 \\
\hline $\begin{array}{l}\text { Knill-Jones et al } \\
1975^{4} \\
\text { Mirakhur et al }\end{array}$ & 435 & Operating room workers & Lifetime & 1st trimester & 435 & Any other work (some did not work) & 0 \\
\hline $\begin{array}{l}1975^{5} \\
\text { Pharoah et al }\end{array}$ & 114 & Anaesthetists & Lifetime & Not specified & 118 & Other physicians (probably working) & 1 \\
\hline $1977^{22}$ & 670 & Physicians, anaesthesia & Lifetime & At time of conception & 6337 & Other physicians (probably working) & 1 \\
\hline Cohen et al $1980^{\circ}$ & 400 & $\begin{array}{l}\text { Dental assistants, high } \\
\text { exposure }\end{array}$ & $10 \mathrm{y}$ & $\begin{array}{l}12-18 \text { months before } \\
\text { conception }\end{array}$ & 8184 & Dental assistants (probably working) & 2 \\
\hline $\begin{array}{l}\text { Lauwerys et al } \\
\qquad 1981^{7}\end{array}$ & 259 & $\begin{array}{l}\text { Operating room physicians, } \\
\text { nurses }\end{array}$ & Lifetime & $\begin{array}{l}\text { During pregnancy or } 1 \text { y } \\
\text { before }\end{array}$ & 1651 & $\begin{array}{l}\text { Physicians, nurses (working status } \\
\text { unknown) }\end{array}$ & 1 \\
\hline $\begin{array}{l}\text { Axelsson et al } \\
1982^{15}\end{array}$ & 139 & $\begin{array}{l}\text { Non-physician hospital } \\
\text { workers, high exposure }\end{array}$ & Lifetime & During pregnancy & 573 & Any other work (some did not work) & 0 \\
\hline \multirow[t]{2}{*}{ Heidam $1984^{18}$} & 179 & $\begin{array}{l}\text { Dental assistants, private } \\
\text { clinics, } \mathrm{N}_{2} \mathrm{O}\end{array}$ & Lifetime & During pregnancy & 80 & $\begin{array}{l}\text { Dental assistants, private clinics } \\
\text { (working) }\end{array}$ & 2 \\
\hline & 76 & $\begin{array}{l}\text { Dental assistants, schools, } \\
\mathrm{N}_{2} \mathrm{O}\end{array}$ & Lifetime & During pregnancy & 17 & Dental assistants, schools (working) & 2 \\
\hline $\begin{array}{l}\text { Ericson and Kallen } \\
1985^{17}\end{array}$ & 1436 & $\begin{array}{l}\text { Anaesthesia, operating room } \\
\text { nurses }\end{array}$ & $6 y$ & $\begin{array}{l}\text { Year of delivery or } 1 \text { y } \\
\text { before }\end{array}$ & 1495 & Internal medicine nurses (working) & 1 \\
\hline $\begin{array}{l}\text { McDonald et al } \\
1986^{20}\end{array}$ & 45 & Operating room nurses & $\begin{array}{l}\text { Current } \\
\text { pregnancy }\end{array}$ & At time of conception & 30919 & Any other work (working) & 0 \\
\hline $\begin{array}{l}\text { McDonald et al } \\
1988^{21}\end{array}$ & 70 & Health workers & $\begin{array}{l}\text { Lifetime } \\
\text { before } \\
\text { current } \\
\text { pregnancy }\end{array}$ & At time of conception & 22543 & Any other work (working) & 0 \\
\hline \multicolumn{8}{|l|}{ Guirguis et al } \\
\hline $\begin{array}{l}\text { Saurel-Cubizolles } \\
\text { et al } 1994^{24}\end{array}$ & 284 & Operating room nurses & $20 \mathrm{y}$ & During pregnancy & 480 & $\begin{array}{l}\text { Nurses, never worked in operating room } \\
\text { (working status unknown) }\end{array}$ & 1 \\
\hline $\begin{array}{l}\text { Rowland et al } \\
1995^{14}\end{array}$ & 356 & $\begin{array}{l}\text { Dental assistants, scavenged } \\
\mathrm{N}_{2} \mathrm{O}\end{array}$ & $\begin{array}{l}\text { Last } \\
\text { pregnancy }\end{array}$ & At last menstrual period & 684 & Dental assistants (working) & 2 \\
\hline
\end{tabular}

* Score for the validity of the unexposed comparison group.

Table 2 Case-control studies of spontaneous abortion in women occupationally exposed to anaesthetic gases

\begin{tabular}{|c|c|c|c|c|c|c|}
\hline \multirow[b]{2}{*}{ Reference } & \multirow[b]{2}{*}{ Sample size } & \multirow[b]{2}{*}{ Exposed group } & \multicolumn{2}{|c|}{ Time window for } & \multicolumn{2}{|l|}{ Unexposed group } \\
\hline & & & $\begin{array}{l}\text { Inclusion of } \\
\text { pregnancies }\end{array}$ & $\begin{array}{l}\text { Occurrence of } \\
\text { exposure }\end{array}$ & Definition (working status) & Score ${ }^{\star}$ \\
\hline $\begin{array}{l}\text { Hemminki et al } 1985^{25} \\
\text { Johnson et al } 1987^{8}\end{array}$ & $\begin{array}{l}169 \text { cases; } 469 \text { controls } \\
\text { Not indicated } \\
\text { Not indicated }\end{array}$ & $\begin{array}{l}\text { Nurses } \\
\text { Veterinarians } \\
\text { Assistant veterinarians }\end{array}$ & $\begin{array}{l}7 \text { y } \\
\text { Lifetime } \\
\text { Lifetime }\end{array}$ & $\begin{array}{l}\text { 1st trimester } \\
1 \text { st trimester } \\
\text { 1st trimester }\end{array}$ & $\begin{array}{l}\text { Nurses (working) } \\
\text { Veterinarians (working) } \\
\text { Assistant veterinarians (working) }\end{array}$ & $\begin{array}{l}1 \\
2 \\
2\end{array}$ \\
\hline
\end{tabular}


We used a scoring system to measure our judgment of the validity of the unexposed comparison groups in the reviewed studies. This scoring system took into account whether or not these women were working, and if they worked, the nature of their occupation. Our scores were:

(1) Highly comparable occupations (score=2). We included here the following comparisons: exposed scrub or anaesthesia nurses versus unexposed working emergency or intensive care nurses, ${ }^{23}$ and exposed versus unexposed working dental assistants ${ }^{61418}$; exposed versus unexposed working veterinarians, ${ }^{8}$ and exposed versus unexposed working assistant veterinarians. ${ }^{8}$ Therefore, in all of these studies, unexposed women were employed.

(2) Similar occupations (score=1). We included here: operating room nurses versus other nurses, ${ }^{716172425}$ anaesthetists versus other physicians, ${ }^{57161922}$ exposed versus unexposed anaesthetists, ${ }^{3}$ exposed versus unexposed nurse anaesthetists, ${ }^{3}$ exposed versus unexposed operating room nurses or technicians, ${ }^{3}$ and exposed versus unexposed hospital workers. ${ }^{9}$ We see that in some of these studies, the employment status of the unexposed women was unclear or unspecified.

(3) Dissimilar occupations (score $=0$ ). We included here: exposed workers compared with women in any other activity, including no work. ${ }^{1519-21}$ Any study which explicitly included unemployed women in the unexposed group received a score of 0 .

EXCLUSION OF NON-INDEPENDENT COMPARISONS In certain studies, more than one unexposed comparison group was used. Knill-Jones et $a l^{19}$ compared anaesthetists exposed to anaesthetic gases during the first or second trimester of pregnancy with anaesthetists who were not working (relative risk: 1.33 ) and also to other physicians whose employment status during pregnancy was not specified (relative risk: 1.24). Because these two estimates of relative risk are not independent, we retained in our meta-analysis only one of the two comparisons-namely, the comparison between exposed anaesthetists and other physicians because we judged that anaesthetists who were not working were more likely to represent a biased comparison group. Similarly, Cohen $e t$ $a l^{\beta}$ compared exposed anaesthetists with unexposed anaesthetists (relative risk: 1.07) and with paediatricians (relative risk: 1.92); the working status of the unexposed women, anaesthetists or paediatricians was not specified, and in our meta-analysis we retained the comparison of exposed and unexposed anaesthetists, which we judged, on the basis of the limited information available to us, to be the comparison presenting less potential for bias. Cohen $e t a \hat{l}$ also compared exposed nurseanaesthetists to unexposed nurse-anaesthetists (relative risk: 1.18) and to non-anaesthetist nurses (relative risk: 1.13), and exposed operating room nurses or technicians to unexposed operating room technicians (relative risk: 1.29) and to non-anaesthetist nurses (relative risk: 1.29); in our meta-analysis, we retained the comparisons of exposed and unexposed nurse-anaesthetists, operating room nurses, and technicians.

Conversely, other studies compared two separate exposure groups with the same unexposed category. Here again, relative risk estimates were not independent, and we chose the comparison which seemed most pertinent for our study question. Cohen et al compared exposed dental assistants with unexposed assistants. Exposure was classified as light or heavy. Light exposure to anaesthetics was defined as one to eight hours of exposure per week (relative risk: 1.75), and heavy exposure as an excess of eight hours per week (relative risk: 2.35$)$. We excluded the data on subjects with low exposure, because they seemed less representative of the amount of exposure to be expected in health workers, particularly hospital workers. Similarly, Rowland et $a l^{14}$ compared exposed dental assistants with unexposed assistants, dividing the exposed subjects into those working in offices that used scavenging equipment (relative risk: 1.0 ) and those in offices without scavenging (relative risk: 1.1). In this case, we retained the subjects working in offices with scavenging, as the use of scavenging is now widely recommended as the normal practice.

\section{CONTROL OF NON-OCCUPATIONAL CONFOUNDING} VARIABLES

Non-occupational variables may also act as confounding factors in these studies. Risk of spontaneous abortion is reported to increase with increasing maternal age, ${ }^{29}$ with smoking, ${ }^{3031}$ with alcohol consumption, ${ }^{30}$ with use of coffee, ${ }^{30}$ and in one study, the odds ratios for the association between exposure to anaesthetic gases and spontaneous abortion were slightly lower when adjustment was made for radiation exposure. ${ }^{8}$

The risk of spontaneous abortion is also reported to increase with parity, ${ }^{20}$ history of previous spontaneous abortion, ${ }^{20}$ and gravidity. ${ }^{21}$ A special difficulty, however, arises with such variables. Weinberg ${ }^{32}$ has shown that determinants of spontaneous abortion such as history of the same outcome should not be adjusted for if these determinants may have been caused in part by the exposure under study-namely here, occupational exposure to anaesthetic gases. In practice, however, it may be difficult or impossible to determine whether the conditions described by Weinberg are present. Because of this, Nurminen ${ }^{34}$ suggested that a reasonable strategy was to present analyses with and without adjustment for pregnancy history.

Table 3 lists the confounding variables which were taken into account in the reviewed studies. Seven of the comparisons summarised in tables 1 and 2 did not control for any non-occupational confounding variable. ${ }^{5716171923}$ The other studies took into account confounding to varying degrees, ranging from adjustment for age only, ${ }^{15225}$ to adjustment in one study for seven variables. ${ }^{21}$ We do not know to what extent 
Table 3 Response rates and control of confounding

\begin{tabular}{|c|c|c|c|c|}
\hline \multirow[b]{2}{*}{ Reference* } & \multicolumn{2}{|c|}{ Response rate } & \multicolumn{2}{|l|}{ Confounding } \\
\hline & $\%$ & Score & Variables controlled & Score \\
\hline Cohen et al $1971^{16}$ & $\begin{array}{l}\text { Not given } \\
77\end{array}$ & $\begin{array}{l}0 \\
1\end{array}$ & $\begin{array}{l}\text { None (exposed } 3.4 \text { y older, smoked more: } 36 \% v 30 \% \text { ) } \\
\text { None (exposed } 2.8 \text { y older) }\end{array}$ & $\begin{array}{l}-1 \\
-1\end{array}$ \\
\hline $\begin{array}{l}\text { Knill-Jones et al } 1972^{19} \\
\text { Rosenberg and Kirves }\end{array}$ & 81 & 2 & None & 0 \\
\hline $1973^{23}$ & $>70$ & 1 & None & 0 \\
\hline Cohen $1974^{3}$ & $\begin{array}{l}76 \\
59 \\
55\end{array}$ & $\begin{array}{l}1 \\
0 \\
0\end{array}$ & $\begin{array}{l}\text { Age, smoking (parity, previous abortions were not confounders) } \\
\text { Age, smoking (parity, previous abortions were not confounders) } \\
\text { Age, smoking (parity, previous abortions were not confounders) }\end{array}$ & $\begin{array}{l}2 \\
2 \\
2\end{array}$ \\
\hline Knill-Jones et al $1975^{4}$ & 70 & 1 & Age (maternal, paternal), smoking, parity & 2 \\
\hline Mirakhur et al $1975^{5}$ & 66 & 1 & None (exposed 2.5 y younger) & -1 \\
\hline Pharoah et al $1977^{22}$ & 72 & 1 & Age (exposed smoked more: $22.9 \%$ v $20.1 \%$ ) & 0 \\
\hline Cohen et al $1980^{6}$ & 70 & 1 & Age, smoking, parity & 2 \\
\hline Lauwerys et al $1981^{7}$ & 47 & 0 & None & 0 \\
\hline Axelsson et al $1982^{15}$ & $>79$ & 2 & Age & 1 \\
\hline Heidam $1984^{18}$ & $\begin{array}{l}94 \\
94\end{array}$ & $\begin{array}{l}2 \\
2\end{array}$ & $\begin{array}{l}\text { Age, gravidity, pregnancy order } \\
\text { Age, gravidity, pregnancy order }\end{array}$ & $\begin{array}{l}2 \\
2\end{array}$ \\
\hline Ericson and Kallen $1985^{17}$ & $>80$ & 2 & None (exposed older and of higher parity) & -1 \\
\hline $\begin{array}{l}\text { McDonald et al } 1986^{20} \\
\text { McDonald et al } 1988^{21}\end{array}$ & 84 & 2 & $\begin{array}{l}\text { Age, smoking, parity, previous abortions, education } \\
\text { Age, smoking, gravidity, previous abortions, education, alcohol, }\end{array}$ & 2 \\
\hline & 84 & 2 & ethnicity & 2 \\
\hline $\begin{array}{l}\text { Guirguis et al } 1990^{\circ} \\
\text { Saurel-Cubizolles et al }\end{array}$ & 81 & 2 & Age, smoking, parity, alcohol, previous abortions & 2 \\
\hline $1994^{24}$ & 85 & 2 & Age, smoking, gravidity, previous abortions, antineoplastic drugs & 2 \\
\hline Rowland et al $1995^{14}$ & 69 & 1 & Age, smoking, gestational week, amalgams/week & 2 \\
\hline Hemminki et al $1985^{25}$ & $>80$ & 2 & Age & 1 \\
\hline Johnson et al $1987^{8}$ & 54 & 0 & Age, parity, $x$ ray films & 2 \\
\hline & 44 & 0 & Age, parity, $x$ ray films & 2 \\
\hline
\end{tabular}

*Some references show results for more than one comparison (see tables 1 and 2).

the absence of control for such nonoccupational variables in several of the reviewed studies actually led to bias.

In conclusion, studies which did not control for factors known or strongly suspected to be associated with the risk of spontaneous abortion could likely be biased. Because of this, reports in which confounding was not taken into account should receive less weight in the overall assessment of the effect of anaesthetic gases on risk of spontaneous abortion than studies which controlled potential confounders. In our meta-analysis, we used the following scoring system:

(1) Control for two or more confounding variables $(s c o r e=2)$. All studies receiving a score of 2 controlled for maternal age, and several controlled for smoking.

(2) Control for one confounding variable $($ score $=1)$. All studies receiving a score of 1 controlled for maternal age.

(3) No control for confounding (score $=0$ ).

When in a given study the authors failed to control for a risk factor which was actually shown to be positively or negatively associated with exposure within the study, the score obtained above was reduced by 1 . For example, the score initially given to the study reported by Pharoah et $a l^{2}$ was 1 , because these authors controlled for one confounding variablenamely, maternal age. However, the authors gave evidence in their paper that exposed women smoked more than the unexposed, and yet they did not adjust their results for smoking. Because of this, our confounding score was reduced by 1 , therefore becoming 0 .

Control for variables related to pregnancy such as gravidity, parity, or history of previous spontaneous abortion was not taken into account in this scoring system. In our metaanalysis, however, we made estimates based both on all available papers, and others in which studies controlling for history of previous spontaneous abortion were excluded.

\section{RESPONSE BIASES IN STUDIES OF SPONTANEOUS} ABORTION

Another potential bias in this type of research is the completeness of ascertainment of cases of spontaneous abortion. Abortion is an end point for which self reporting can be inaccurate. Furthermore, the time intervals considered in the published studies ranged from review of the current pregnancy only, to the assessment of the entire reproductive history. Because of this, research on this outcome may be affected by recall bias. This was shown in one study which compared responses about pregnancy outcomes with data from medical records, and in which important errors as to the week of pregnancy in which the spontaneous abortions occurred were found. ${ }^{35}$

Table 3 shows that in the reviewed studies, response rates ranged from $44 \%$ to $94 \%$. In some cases, the authors found differences in response rates between exposed and unexposed subjects. ${ }^{915}$ Low response rates, and response rates which differ between exposed and unexposed women, or cases and controls, suggest that a bias may be present. One major concern is that exposed women who have experienced a spontaneous abortion may respond in higher proportion to a questionnaire than unexposed women or exposed women without spontaneous abortion. Thus suspicion of bias is higher when response rates are low or differential. However, bias can exist even when these rates are high and similar in exposed and unexposed women, or cases and controls. Axelsson and Rylander ${ }^{15}$ conducted a postal survey of non-physician female personnel in a hospital. They also collected information from hospital records on those who did not respond to the questionnaire. They found 
Table 4 Relative risks (RRs), weights, and global scores

\begin{tabular}{llcl}
\hline Reference & $R R(95 \%$ CI) & 1/var (nn RR) & Global score \\
\hline Cohen et al $1971^{16}$ & $3.15(0.95$ to 10.5$)$ & 2.7 & 0 \\
& $3.66(1.54$ to 8.67$)$ & 5.2 & 1 \\
Knill-Jones et al $1972^{19}$ & $1.24(1.03$ to 1.49$)$ & 113.4 & 3 \\
Rosenberg and Kirves $1973^{23}$ & $1.72(1.03$ to 2.86$)$ & 14.6 & 3 \\
Cohen $1974^{3}$ & $1.07(0.67$ to 1.72$)$ & 17.3 & 4 \\
& $1.18(0.95$ to 1.47$)$ & 81.6 & 3 \\
Knill-Jones et al $1975^{4}$ & $1.29(1.08$ to 1.55$)$ & 118.4 & 3 \\
Mirakhur et al $1975^{5}$ & $2.71(1.73$ to 4.24$)$ & 19.1 & 3 \\
Pharoah et al $1977^{22}$ & $3.11(1.37$ to 7.02$)$ & 5.8 & 1 \\
Cohen et al $1980^{6}$ & $1.01(0.83$ to 1.23$)$ & 101.5 & 2 \\
Lauwerys et al $1981^{7}$ & $2.35(2.07$ to 2.65$)$ & 255.1 & 5 \\
Axelsson et al $1982^{15}$ & $1.35(0.87$ to 2.1$)$ & 19.8 & 1 \\
Heidam $1984^{18}$ & $1.19(0.67$ to 2.12$)$ & 11.6 & 3 \\
& $0.9(0.4$ to 2.1$)$ & 5.8 & 6 \\
Ericson and Kallen $1985^{17}$ & $0.3(0.0$ to 1.8$)$ & 1.2 & 6 \\
McDonald et al $1986^{20}$ & $1.04(0.78$ to 1.39$)$ & 46.2 & 2 \\
McDonald et al $1988^{21}$ & $0.29(0.01$ to 16$)$ & 0.2 & 4 \\
Guirguis et al $1990^{9}$ & $1.07(0.67$ to 1.72$)$ & 17.0 & 4 \\
Saurel-Cubizolles et al $1994^{24}$ & $1.98(1.53$ to 2.56$)$ & 57.8 & 5 \\
Rowland et al $1995^{14}$ & $1.9(1.1$ to 3.5$)$ & 12.9 & 5 \\
Hemminki et al $1985^{25}$ & $1.0(0.8$ to 1.1$)$ & 77.2 & 5 \\
Johnson et al $1987^{8}$ & $1.2(0.7$ to 2.4$)$ & 13.2 & 4 \\
& $2.86(0.86$ to 9.53$)$ & 2.7 & 4 \\
& $2.25(0.92$ to 5.52$)$ & 4.8 & 4
\end{tabular}

$\star 95 \%$ CIs presented in the reviewed papers; when the authors did not present such limits, we gave our own estimates.

Table 5 Meta-analysis: relative risk of spontaneous abortion after occupational exposure to anaesthetic gases, by study characteristics

\begin{tabular}{lcl}
\hline Study characteristic & $\begin{array}{l}\text { Number of relative } \\
\text { risk estimates }\end{array}$ & Relative risk (95\% CI) \\
\hline All studies & 24 & $1.48(1.4$ to 1.58$)$ \\
Follow up studies & 21 & $1.48(1.39$ to 1.58$)$ \\
Case-control studies & 3 & $1.55(1.01$ to 2.39$)$ \\
Response rate $\geqslant 80 \%$ & 10 & $1.32(1.17$ to 1.48$)$ \\
Control of $\geqslant 2$ non-occupational confounding & 14 & $1.65(1.53$ to 1.78$)$ \\
$\quad$ variables & 14 & $1.89(1.7$ to 2.09$)$ \\
Highly comparable unexposed comparison group & 7 & $1.48(1.39$ to 1.58$)$ \\
Global validity score $\geqslant 1$ & 23 & $1.57(1.47$ to 1.68$)$ \\
Global validity score $\geqslant 3$ & 18 & $1.9(1.72$ to 2.09$)$ \\
Global validity score $\geqslant 5^{\star}$ & 6 &
\end{tabular}

*There was only one study with the maximum score of 6 , in which the author found a decreased risk (not significant) of spontaneous abortion in dental assistants exposed to $\mathrm{N}_{2} \mathrm{O}^{16}$

that among these, all spontaneous abortions occurred in women working in areas without exposure to anaesthetic gas. Unexposed nonrespondents had a higher rate of spontaneous abortion than unexposed respondents. This shows that despite small differences in response rates between exposed and unexposed groups, in this case $80 \%$ versus $78 \%$, there can be a selection in the non-respondent group for exposure status and pregnancy outcome. In this study, the addition of the results on non-respondents to the data changed the conclusion from a significant effect to a lack of significance.

Data reported by $\mathrm{McDonald}$ et $a l^{20}$ showed that a favourable response rate may be obtained even in the presence of a poor ascertainment of spontaneous abortion. These authors succeeded in interviewing $90 \%$ of all women delivering a baby in 11 hospitals in Montréal (Canada) (28 698 women) and about $75 \%$ of those with spontaneous abortion (2266 women). They indicated, however, that only about $60 \%$ of the cases of spontaneous abortion were admitted to hospital, which leads to a response rate of $75 \% \times 60 \%=45 \%$ for the cases of abortion. These data suggest that about 3189 deliveries of babies were missed, and 2770 cases of spontaneous abortion. Overall, however, this translates into an excellent response rate of $84 \%$, reflecting the fact that in this type of study design, the global response rate is heavily influenced by the response rate among women delivering a baby.

Despite the difficulties in the interpretation of response rates and in the assessment of their impact on the validity of results, we judged that studies with better response rates should receive more weight than those with poor response rates. In our subsequent analysis of these studies, we used the following scoring system:

(1) Response rate $\geqslant 80 \%$ (score $=2$ ).

(2) $60 \%$ to $79 \%$ (score $=1$ ).

(3) $<60 \%$ (score $=0$ ). A score of zero was also given when no response rate was provided by the authors.

Response rates were not always defined precisely, or when defined, the definitions varied between authors. For example, in certain studies, the denominator used to determine the response rate was all of the distributed questionnaires. ${ }^{5-79141518}$

Other authors excluded from the denominator all posted questionnaires which could not be delivered because of an unknown address. ${ }^{41922}$ In other studies, the population considered for the calculation of the response rate was restricted to pregnant women, as opposed to all women in a specific population. ${ }^{82021}$

Ericson and Källén ${ }^{17}$ and Hemminki et $a l^{25}$ did not give response rates for their studies, because they were registry based. Registry based studies offer the advantage of using data which cannot be biased by respondents. Because a very large proportion of spontaneous abortions do not lead to admission to hospital, however, such registries present the same difficulty as the hospital based study already discussed, ${ }^{20}$ so the ascertainment of spontaneous abortions is poor. On the other hand, the overall ascertainment of pregnancies is high, and taking into consideration the results of our calculations for the report by $\mathrm{McD}$ Donald et $a l^{20}$ it is most likely that the proportion of pregnancies ascertained in these registry studies, which can be seen as the equivalent of the response rate in the other studies, was $>80 \%$.

Saurel-Cubizolles $e t a l^{4}$ did not give a response rate in the report which we used for the meta-analysis. Their response rate was, however, given in an earlier publication. ${ }^{36}$

\section{Results}

Table 4 gives the relative risk estimates of spontaneous abortion obtained in each study. A total of 24 comparisons between exposed and unexposed women were retained from the 19 reviewed reports. Table 5 gives results of our meta-analysis. The overall relative risk was 1.48 ( $95 \%$ confidence interval ( $95 \%$ CI) 1.4 to 1.58).

To be able to interpret relative risks in terms of absolute increase in risk, we calculated the risk of spontaneous abortion in all unexposed women in the 17 follow up studies included in our review. There were 80368 pregnancies in the unexposed women described in table 1 , and the overall risk of spontaneous abortion, calculated from data given in the correspond- 
Table 6 Meta-analysis: relative risk of spontaneous abortion in selected subgroups

\begin{tabular}{lll}
\hline Occupation & $\begin{array}{l}\text { Number of relative } \\
\text { risk estimates }\end{array}$ & $\begin{array}{l}\text { Relative risk (95\% } \\
\text { CI) }\end{array}$ \\
\hline All studies & 24 & 1.48 (1.4 to 1.58) \\
$\quad$ Hospital workers: & 18 & $1.3(1.21$ to 1.41$)$ \\
$\quad$ All studies & 5 & $1.18(1.04$ to 1.34$)$ \\
$\quad$ Restricted to physicians & 13 & $1.38(1.26$ to 1.52$)$ \\
$\quad$ Others (may include physicians) & 10 & $1.27(1.16$ to 1.39$)$ \\
$\quad$ Studies published in 1971-9 & 8 & $1.41(1.21$ to 1.63$)$ \\
$\quad$ Studies published in 1980-95 & 4 & $1.89(1.7$ to 2.1$)$ \\
Dental assistants & 2 & $2.45(1.25$ to 5.02$)$ \\
Veterinarians and veterinary assistants & &
\end{tabular}

ing papers, was $13 \%$. A relative risk of 1.48 corresponds therefore to an increase in the absolute risk of abortion of $6.24 \%(=(13 \% \times$ $1.48)-13 \%)$.

We also obtained relative risk estimates for selected occupations. Table 6 shows that relative risks were higher for dental assistants, veterinarians, and assistant veterinarians than for hospital workers. The relative risk for studies of hospital workers published in 1980-95 was slightly larger than the relative risk for earlier studies.

The estimated relative risk of 1.48 proved to be fairly robust to exclusions of studies of possibly lower validity. The estimate increased to 1.57 when studies with a score $\geqslant 3$ were considered, and to 1.9 when only studies with a score $\geqslant 5$ were included. We repeated all of the analyses shown in table 5, restricted to papers in which history of spontaneous abortion was not included as a confounding variable: all estimates remained similar.

\section{Discussion}

We identified 19 epidemiological studies of the association between maternal occupational exposure to anaesthetic gases and risk of spontaneous abortion. Epidemiological research in this domain presents several methodological difficulties, including: (a) problems in selecting groups of exposed and unexposed women which are comparable for risk factors of spontaneous abortion, for everything other than exposure to anaesthetic gases; $(b)$ inadequate control for confounding effects when the contrasted groups are not comparable for such risk factors; and $(c)$ potential biases arising from imperfect response rates to survey questionnaires or other research instruments. Each of the 19 reviewed studies was attributed a score based on these three factors to reflect our judgment of the validity of the reported data. The 19 studies showed a broad range of results going from reduced risk of spontaneous abortion in exposed women to an increased risk. Overall, when all available studies were included in the meta-analysis, a relative risk of 1.48 was obtained (95\% CI: 1.4 to 1.58 ). Similar results were obtained with follow up studies and case-control studies. The relative risk varied according to occupation, ranging from 1.18 among physicians to 2.45 in veterinarians and veterinary assistants. Year of publication of the study did not influence the relative risk.

Our analysis was restricted to published peer reviewed papers for two reasons. Firstly, it is likely that a factor explaining why a study remains unpublished is that it is methodologically weak. Inclusion of such studies may then compromise the validity of a meta-analysis. ${ }^{37} 38$ Secondly, a commonly cited explanation for failure to publish is that negative results are "uninteresting" (publication bias). In the present situation, however, publication bias seems unlikely as both positive and negative results would be of equal interest.

The use of a global quality score in meta-analysis is controversial. Such scores should not be viewed as objective assessments of study characteristics. ${ }^{39}$ Of necessity they must be based on the judgment of the authors (and in this case the judgment of others ${ }^{40-42}$ ) about the impact of specific study features on the validity of results. We also calculated separately the relative risks according to each component of the quality score (table 5). None of these analyses significantly influenced the overall conclusion-namely, that exposure, in these studies, was related to increased risk of spontaneous abortion.

Buring et $a l^{40}$ pooled data from five studies published between 1971 and 1978..$^{315161923}$ They concluded that there was reasonably consistent evidence for an association between exposure to anaesthetic gases of pregnant women and adverse reproductive outcome, and estimated the maximum magnitude of the relative risk for spontaneous abortion to be of the order of 1.3 (95\% CI 1.2 to 1.4 ) for physicians and nurses. Their estimate was therefore similar to the one we obtained in our meta-analysis when we included all available studies. The authors commented that such a small increase in relative risk was well within the range that can be attributed to response bias, recall bias, and confounding. Vessey ${ }^{41}$ examined seven epidemiological studies of spontaneous abortion $^{341619222343}$ and also concluded that there was reasonable evidence for a moderate increase in risk among exposed women. $\mathrm{He}$ too considered that this result could be attributed to reporting bias. He also suggested that an increase in spontaneous abortion among women working in anaesthesia might be due to the emotional and physical rigours of the occupation, and not to exposure to the gases. Tannenbaum and Goldberg ${ }^{42}$ reviewed 10 epidemiological studies of spontaneous abortion in women exposed to anaesthetic gases $^{3467101115161923}$ and concluded that serious methodological flaws undermined the validity of these studies, and that consistency of their results could be partly explained by the consistency of their methodological problems.

Conditions in operating rooms have changed since most of the reviewed epidemiological studies were carried out. Intravenous anaesthetics and local analgesia are used increasingly, and the scavenging of waste anaesthetic gases is now the rule in Canada, the United States, and most European countries. These measures have significantly reduced concentrations of anaesthetic gases relative to previous concentrations. Whether such low levels of exposure remain associated with an increased risk of spontaneous abortion is unknown. The epidemiological studies published to date pro- 
vide very little information on the relation between amount of exposure and magnitude of risk. The limited available data suggest, however, that risk of spontaneous abortion may be low $^{6}$ or absent ${ }^{14}$ when gases are scavenged or when the exposure to unscavenged gases is low.

In summary, epidemiological data generally indicate an increased risk of spontaneous abortion in women occupationally exposed to anaesthetic gases. Experimental data also indicate that exposure to anaesthetic gases is associated with harmful reproductive effects in animals. ${ }^{44-47}$ Several methodological problems make the interpretation of epidemiological studies difficult, and we conclude along with other reviewers that the associations found may be due as much to biases from confounding variables and response rates as to really harmful effects of these gases. However, when we attempted to control for these biases by selecting in our meta-analysis those studies most likely to provide valid results, the estimate of risk of spontaneous abortion was increased rather than diminished. These analyses, along with the concordance of findings between epidemiological and animal data, suggest that a real risk may be present. The epidemiological (and animal) data also suggest that harmful effects may be reduced or even abolished when gases are scavenged or when exposure to unscavenged gases is low.

I thank Dr Maurice McGregor for his support and advice.

1 National Institute for Occupational Safety and Health. NIOSH Alert. Request for assistance in controlling exposures to nitrous oxide during anesthetic administration. Cincinnati, OH: Centers for Disease Control and Prevention, NIOSH; 1994. (DHHS (NIOSH) Publ No 94-100.)

2 Cohen EN, Brown BW Jr, Bruce DL, Cascorbi HF, Corbett Cohen EN, Brown BW Jr, Bruce DL, Cascorbi HF, Corbett
TH, Jones TW, Whitcher CE. A survey of anesthetic health TH, Jones TW, Whitcher CE. A survey of anesthetic health
hazards among dentists. $\mathcal{F}$ Am Dent Assoc 1975;90:1291-6. 3 Cohen EN. Ad Hoc Committee on the Effect of Trace Anesthetics on the Health of Operating Room Personnel, American Society of Anesthesiologists. Occupational disease among operating room personnel: a national study. Anesthesiology 1974;41:321-40.

4 Knill-Jones RP, Newman BJ, Spence AA. Anaesthetic practice and pregnancy. Controlled survey of male anaesthetists in the United Kingdom. Lancet 1975;ii:807-9.

5 Mirakhur RK, Badve AV. Pregnancy and anaesthetic practice in India. Anaesthesia 1975;30:18-22.

6 Cohen EN, Gift HC, Brown BW, Greenfield W, Wu ML Cohen EN, Gift HC, Brown BW, Greenfield W, Wu ML,
Jones TW, et al. Occupational disease in dentistry and chronic exposure to trace anesthetic gases. $\mathcal{F} \mathrm{Am}$ Dent Assoc chronic exposure

7 Lauwerys R, Siddons M, Misson CB, Borlee I, Bouckaert A, Lechat MF, De Temmerman P. Anaesthetic health hazards among Belgian nurses and physicians. Int Arch Occup Environ Health 1981;48:195-203.

8 Johnson JA, Buchan RM, Reif JS. Effect of waste anesthetic gas and vapor exposure on reproductive outcome in veterinary personnel. Am Ind Hyg Assoc $\mathcal{F}$ 1987;48:62-6.

9 Guirguis SS, Pelmear PL, Roy ML, Wong L. Health effects associated with exposure to anaesthetic gases in Ontario associated with exposure to anaesthetic gases in
hospital personnel. Br f Ind Med 1990;47:490-7.

10 Rosenberg PH, Vänttinen H. Occupational hazards to reproduction and health in anaesthetists and paediatrireproduction and health in anaesthetists and
cians. Acta Anaesthesiol Scand 1978;22:202-7.

11 Tomlin PJ. Health problems of anaesthetists and their families in the West Midlands. BMF 1979;1:779-84.

12 Rothman KJ. Modern epidemiology. Boston: Little Brown, 1986.

13 Prentice RL, Thomas DB. On the epidemiology of oral contraceptives and disease. Adv Cancer Res 1987;49:285-401.

14 Rowland AS, Baird DD, Shore DL, Weinberg CR, Savitz DA, Wilcox AJ. Nitrous oxide and spontaneous abortion in female dental assistants. Am $\mathcal{f}$ Epidemiol 1995;141:531-8.

15 Axelsson G, Rylander R. Exposure to anaesthetic gases and spontaneous abortion: response bias in a postal questionnaire study. Int $\mathcal{F}$ Epidemiol 1982;11:250-6.

16 Cohen EN, Bellville JW, Brown BW. Anesthesia, pregnancy, and miscarriage: a study of operating room nurses and anesthetists. Anesthesiology 1971;35:343-7.
17 Ericson HA, Källén AJB. Hospitalization for miscarriage and delivery outcome among Swedish nurses working in operating rooms 1973-8. Anesth Analg 1985;64:981-8.

18 Heidam LZ. Spontaneous abortions among dental assistants, factory workers, painters, and gardening workers: a follow up study. $\mathcal{F}$ Epidemiol Community Health 1984;38: 149-55.

19 Knill-Jones RP, Rodrigues LV, Moir DD, Spence AA. Anaesthetic practice and pregnancy. Controlled survey of women anaesthetists in the United Kingdom. Lancet 1972; i:1326-8.

20 McDonald AD, Armstrong B, Cherry NM, Delorme C, Diodati-Nolin A, McDonald JC, Robert D. Spontaneous abortion and occupation. $\mathcal{F}$ Occup Med 1986;28:1232-8.

21 McDonald AD, McDonald JC, Armstrong B, Cherry NM, Côté R, Lavoie J, et al. Fetal death and work in pregnancy. Br F Ind Med 1988;45:148-57.

22 Pharoah POD, Alberman E, Doyle P. Outcome of pregnancy among women in anaesthetic practice. Lancet 1977;i:34-6.

23 Rosenberg P, Kirves A. Miscarriages among operating theatre staff. Acta Anaesthesiol Scand 1973;suppl 53:37-42.

24 Saurel-Cubizolles MJ, Hays M, Estryn-Behar M. Work in operating rooms and pregnancy outcome among nurses. Int Arch Occup Environ Health 1994;66:235-41.

25 Hemminki K, Kyyrönen P, Lindbohm M-L. Spontaneous abortions and malformations in the offspring of nurses exposed to anaesthetic gases, cytostatic drugs, and other potential hazards in hospitals, based on registered information of outcome. $\mathcal{f}$ Epidemiol Community Health 1985;39:141-7.

26 National Center for Health Statistics. International classification of diseases, adapted for use in the United States, vol classification of diseases, adapted for use in the United States, vol Statistics, 1968. (Public Health Service Publ No 1693.)

27 Savitz DA, Whelan EA, Rowland AS, Kleckner RC. Maternal employment and reproductive risk factors. Am $\mathcal{f}$ Epidemiol 1990;132:933-45.

28 Klebanoff MA, Shiono PH, Rhoads GG. Outcomes of pregnancy in a national sample of resident physicians. $N$ Engl f Med 1990;323:1040-5.

29 Risch HA, Weiss NS, Clarke EA, Miller AB. Risk factors for spontaneous abortion and its recurrence. Am $\mathcal{f}$ Epidemiol 1988;128:420-30.

30 Armstrong $\mathrm{BG}$, McDonald $\mathrm{AD}$, Sloan $\mathrm{M}$. Cigarette, alcohol, and coffee consumption and spontaneous abortion. Am f Public Health 1992;82:85-7.

31 Kline J, Levin B, Kinney A, Stein Z, Susser M, Warburton D. Cigarette smoking and spontaneous abortion of known karyotype. Precise data but uncertain inferences. Am $\mathcal{F}$ Epidemiol 1995;141:417-27.

32 Weinberg CR. Toward a clearer definition of confounding. Am f Epidemiol 1993;137:1-8.

33 Weinberg CR. Should we adjust for pregnancy history when the exposure effect is transient? Epidemiology 1995;6:3356.

34 Nurminen T. Should we adjust for pregnancy history when the exposure effect is transient? Epidemiology 1995;6:336-

35 Axelsson G, Rylander R. Validation of questionnaire reported miscarriage, malformation and birth weight. Int $\mathcal{f}$ Epidemiol 1984;13:94-8.

36 Estryn-Béhar M, Saurel-Cubizolles MJ, Maillard MF, Mugnier N, Saint-Maurice C. Conditions de travail des personnels des blocs opératoires: symptômes divers observés et issue des grossesses. Cah Anesthesiol 1993;41:453-8.

37 Dickersin K. The existence of publication bias and risk factors for its occurrence. $¥ A M A 1990 ; 263: 1385-9$.

38 Cook DJ, Guyatt GH, Ryan G, Clifton J, Buckingham L, Willan A, et al. Should unpublished data be included in meta-analyses? Current convictions and controversies. fAMA 1993;269:2749-53.

39 Greenland S. Invited commentary: a critical look at some popular meta-analytic methods. Am f Epidemiol 1994;140: 290-6.

40 Buring JE, Hennenkens $\mathrm{CH}$, Mayrent SL, Rosner B, Greenberg ER, Colton T. Health experiences of operating room personnel. Anesthesiology 1985;62:325-30.

41 Vessey MP. Epidemiological studies of the occupational hazards of anaesthesia - a review. Anaesthesia 1978;33:4308.

42 Tannenbaum TN, Goldberg RJ. Exposure to anesthetic gases and reproductive outcome. $\mathcal{F}$ Occup Med 1985;27: 659-68.

43 Askrog V, Harvald B. Teratogen effekt af inhalationsanaestetika. Nordisk Medicin 1979;16:498-500.

44 Corbett TH, Cornell RG, Endres JL, Millard RI. Effects of low concentrations of nitrous oxide on rat pregnancy. Anesthesiology 1973;39:299-301.

45 Vieira E. Effect of the chronic administration of nitrous oxide $0.5 \%$ to gravid rats. Br $\mathcal{F}$ Anaesth 1979;51:283-7.

46 Vieira E, Cleaton-Jones P, Austin JC, Moyes DG, Shaw R. Effects of low concentrations of nitrous oxide on rat fetuses. Anesth Analg 1980;59:175-7.

47 Vieira E, Cleaton-Jones P, Moyes D. Effects of low intermittent concentrations of nitrous oxide on the developing rat fetus. $\operatorname{Br} \mathcal{F}$ Anaesth 1983;55:67-9. 